\title{
The Structure and Measurement of Career Indecision: A Critical Review
}

Hui Xu

Loyola University Chicago, hxu2@luc.edu

Cecile $\mathrm{H}$. Bhang

Follow this and additional works at: https://ecommons.luc.edu/education_facpubs

Part of the Education Commons

\section{Author Manuscript}

This is a pre-publication author manuscript of the final, published article.

\section{Recommended Citation}

Xu, Hui and Bhang, Cecile H.. The Structure and Measurement of Career Indecision: A Critical Review. The Career Development Quarterly, , : 2019. Retrieved from Loyola eCommons, Education: School of Education Faculty Publications and Other Works, http://dx.doi.org/10.1002/cdq.12159

This Article is brought to you for free and open access by the Faculty Publications and Other Works by Department at Loyola eCommons. It has been accepted for inclusion in Education: School of Education Faculty Publications and Other Works by an authorized administrator of Loyola eCommons. For more information, please contact ecommons@luc.edu. c) (†) $\ominus$

This work is licensed under a Creative Commons Attribution-Noncommercial-No Derivative Works 3.0 License. (C) 2019 by the National Career Development Association. 
The Structure and Measurement of Career Indecision: A Critical Review

Hui Xu and Cecile H. Bhang

Loyola University Chicago

(Accepted for publication on Career Development Quarterly)

Correspondence should be addressed to Hui Xu, Counseling Psychology, School of Education, Loyola University Chicago, 820 N. Michigan Avenue, Chicago, IL 60611, USA (hxu2@luc.edu). 


\begin{abstract}
This article provides a comprehensive review of the theoretical and empirical progress of indecision structural models and assessment from 2000 to 2017. Because career indecision remains a central topic for career counseling, it is important for the field to achieve an updated understanding of its models and measurement. Based on the development of theory-driven and data-driven indecision models and measures, the review generally found that the Career Decision Difficulties Questionnaire, the Emotional and Personality Career Difficulties Scale, and the Career Indecision Profile could reliably and validly measure various factors of career indecision. It was also found that an integrative five-factor model of indecision (i.e., neuroticism/negative affectivity, choice/commitment anxiety, need for information, lack of readiness, and interpersonal conflicts) shows the potential to adequately represent the comprehensive factor structure of career indecision. Implications and recommendations for practice and research are discussed in a global context.
\end{abstract}

Key words: Career indecision, structural model, measurement, literature review, progress 


\section{The Structure and Measurement of Career Indecision: A Critical Review}

Career indecision remains a core topic in career development and career counseling over the past century (Hacker, Carr, Abrams, \& Brown, 2013; Lipshits-Braziler, Gati, \& Tatar, 2016; Osipow, 1999) reflecting the persistent theoretical proposition that career decision making is a significant but difficult life task across developmental stages (Super, 1994). Much scholarly attention has been given to structural models and measurement of career indecision (e.g., Brown et al., 2012; Chartrand, Robbins, Morrill, \& Boggs, 1990; Gati, Krausz, \& Osipow, 1996;

Germeijs \& De Boeck, 2003; Saka, Gati, \& Kelly, 2008). That is because this has an important practical role in career counseling. More than a decade ago, Osipow (1999) summarized the literature in the area of indecision models and measurement. However, since then, there have been no articles synthesizing the important theoretical and empirical progress of indecision models and measurement (e.g., Brown, et al., 2012; Hacker, et al., 2013; Xu, Hou, \& Tracey, 2014; Xu \& Tracey, 2015b). To provide counselors and researchers with an updated understanding of indecision structure and measurement, we review the theoretical and empirical progress of relevant literature from 2000 to 2017.

\section{The Construct and Measurement of Career Indecision}

Career indecision is a common, if not the most common, presenting issue for career counseling (Lipshits-Braziler, et al., 2016; Osipow, 1999). While career indecision generally denotes a state of being undecided about one’s educational, occupational, or career-related path, it holds a variety of definitions in the literature reflecting different perspectives on the role of career indecision in one's career development. Historically, career indecision has been defined as an inability to make an occupational or educational decision when asked to do so, and a delay in bringing closure to the career decision-making process (Osipow, 1999; Slaney, 1988). This 
traditional definition adopts a linear conceptualization of career decision-making and portrays career indecision as a barrier in career development. Conversely, contemporary definitions of career indecision emphasize a normative or even positive role of career indecision in one's career development and characterize career indecision as a wavering, pause, or hesitation in career development (Savickas, 2011), an openness to alternative career pathways (Krumboltz, 2009), and a state of adaptive uncertainty (Krieshok, Black, \& McKay, 2009; Phillips, 1997). It thus appears reasonable to argue that career indecision holds different meanings for career development, depending on people's objective circumstance and subjective narrative of career decision-making (Savickas, 2015). To achieve an inclusive definition of career indecision, we define career indecision as a state of being undecided about one's educational, occupational, or career-related path.

Although contemporary career counseling does not necessarily regard career decidedness as a counseling goal (Krumboltz, 2009; Savickas, 2015), career indecision is often considered as a concern by people walking into career counseling. To help clients reduce indecision, research has focused on two parameters of career indecision: levels of career indecision and sources of career indecision (Gati, et al., 1996; Osipow, 1999). While career decidedness denotes levels of career indecision with undecided and decided as the two contrasting anchors, career decisionmaking difficulties denote direct sources of one’s career indecision (Gati, et al., 1996; Osipow, 1999). In other words, career decision-making difficulties describe precipitating factors of career undecidedness, and thus its measurement could provide diagnostic information for career counseling (Gati, et al., 1996; Xu \& Tracey, 2017b). In addition to career indecision, there are several similar and correlating constructs regarding career decision-making, such as career choice certainty (e.g., Tracey, 2010) and career commitment (e.g., Blustein, 1989). Career 
choice certainty and career commitment are similar to career decidedness in their assessment of career decision-making status; however, they focus more on perception of an existing career choice.

To inform career counseling, it appears beneficial to focus on career decision-making difficulties when investigating career indecision. Individuals at different life stages could encounter decision-making difficulties for various reasons, such as lack of information or disapproval from important people. It is plausible to argue that different reasons of career indecision would require different intervention strategies, and it is hard for a universal strategy to be equally effective for different presentations of career indecision (Gati, et al., 1996; Osipow, 1999). Therefore, it is clinically important and necessary to assess causes of indecision in career counseling. With such information, counselors will be able to design more appropriate interventions customized to client needs.

\section{Previous Development of Indecision Structure and Measurement}

Indecision measurement refers to a process in which counselors assess a client's major sources of career indecision (i.e., career decision-making difficulties) and is thus clinically important. However, measurement of career indecision heavily relies on a structural model of career indecision, which depicts factors of career decision-making difficulties, and should not be discussed without its structural model. In general, there are two approaches in exploring the structure of career indecision: theory-driven and data-driven (Osipow, 1999). A theory-driven approach uses a predetermined factor structure based on a decision-making theory and incorporates items sampling each indecision domain. In contrast, a data-driven approach relies on empirical data as the predominant source for the factor structure of career indecision. 
Use of theory- and data-driven models in indecision measurement has been discussed previously in Osipow’s (1999) seminal essay, which summarized three generations of indecision measurement marked by three important indecision measures: the Career Decision Scale (CDS; Osipow, Carney, \& Barak, 1976), the Career Factors Inventory (CFI; Chartrand, et al., 1990), and the Career Decision Difficulties Questionnaire (CDDQ; Gati, et al., 1996). Among them, the CDS was originally developed by Osipow and his colleagues as a diagnostic tool for determining differential treatments, but it is often used as a one-dimensional research tool (Osipow, 1999; Osipow, 1994). The CFI was rationally developed based on a dichotomous model of indecision domains, consisting of lack of information and affective/personality-related impediments (Chartrand, et al., 1990). It thus represents a multidimensional theoretical approach to indecision measurement. In contrast to the CDS and the CFI, the CDDQ was later developed based on a taxonomy of indecision resulting from an adaptation of a decision-making theory to the context of career decision-making (Gati, et al., 1996). It proposed ten subdomains and three overarching domains of career indecision, consisting of lack of readiness (LR), lack of information (LI), and inconsistent information (II).

While the CDS and the CFI are still used (e.g., Constantine \& Flores, 2006; Downing \& Nauta, 2010), research on their psychometric properties has been rare. In contrast, the CDDQ has grown to become the latest representative of the multidimensional theory-driven approach of indecision measurement with much new research examining its psychometric properties (e.g., Gati \& Saka, 2001b; Leung, Hou, Gati, \& Li, 2011; Nauta, 2012; Vertsberger \& Gati, 2016; Xu, et al., 2014). Additionally, there have been several new theory- or data-driven measures of career indecision emerging to address issues of the CDDQ (Brown, et al., 2012; 
Saka, et al., 2008). To help career counselors update their assessment of career indecision, it is imperative to review these important areas of progress.

\section{Purpose of the Review}

Since Osipow’s (1999) summary of indecision models and measurement, there has been significant progress in those areas. With career decision-making difficulty as the guiding definition of career indecision, we reviewed the literature on the empirical and theoretical progress of indecision structural models and measurement from 2000 to 2017. As theory- and data-driven approaches hold distinct epistemological perspectives on indecision structure, we reviewed the progress of the two approaches separately to better reveal overlaps and differences among indecision structural models and measures.

\section{Method}

We adopted a two-step approach in identifying relevant articles published between 2000 and 2017. Using the keywords career indecision or career decision-making difficulty, the first general search identified articles in PsycARTICLES and Google Scholar, and the second specific search identified articles in ten professional journals, consisting of Career Development Quarterly, Journal of Vocational Behavior, Journal of Counseling Psychology, Journal of Career Assessment, Journal of Career Development, Journal of Counseling and Development, Journal of Applied Psychology, Journal of Employment Counseling, and International Journal for Educational and Vocational Guidance. We selected final articles to review based on articles’ direct relevance to indecision structural models and measurement. To achieve a comprehensive review, we did not specify any limits on accessibility and cost of measures in the literature search. However, through the review we found that all identified measures are free for clinical and research use upon request. 


\section{Results}

\section{Theory-Driven Models of Indecision}

The Career Decision Difficulties Questionnaire (CDDQ; Gati, et al., 1996) and the Emotional and Personality Career Difficulties Scale (EPCD) (Saka, et al., 2008) were two representative models and measures of the theory-driven approach. The CDDQ focuses more on a rational process of career decision-making and the EPCD focuses more on emotional and personality-related factors of career indecision (Saka \& Gati, 2007; Saka, et al., 2008). The distinction echoes the differentiation between developmental indecision (Osipow, 1999; Tinsley, 1992) and chronic indecisiveness (Germeijs, Verschueren, \& Soenens, 2006; Santos \& J., 2001). The EPCD model proposed a taxonomy of emotional and personality-related indecision with three overarching factors: pessimistic views, anxiety, and self-concept and identity (Saka, et al., 2008). We present evidence of their reliability, structural validity, and criterion-related validity separately.

Reliability of the CDDQ. There have been several areas of progress regarding the psychometric performance of the CDDQ. As for reliability, one consistent finding is the relatively low internal consistency of the lack of readiness (LR) subscale (e.g., Gati \& Saka, 2001b; Leung, et al., 2011; Nauta, 2012; Vertsberger \& Gati, 2016; Xu, et al., 2014). It has been shown that while the alpha coefficients of the lack of information (LI) and inconsistent information (II) subscales typically landed in the .80-.95 range, the alpha coefficient of the LR subscale often landed in the .50-.70 range (Gati \& Saka, 2001b; Leung, et al., 2011; Nauta, 2012; Vertsberger \& Gati, 2016; Xu, et al., 2014; Xu \& Tracey, 2015a). This finding is consistent with Gati et al.'s (1996) original scale development study, showing that the three subdomains underlying the LR (i.e., lack of motivation, indecisiveness, and dysfunctional beliefs) might 
represent distinct aspects of career indecision. Although Gati et al. (1996) underlined the importance of including these three indecision factors, based on the empirical evidence it appears more reasonable to treat these three factors as distinct. Xu and Tracey’s (2014) study represented such an approach to the revision of the CDDQ model and proposed a five-factor structure with lack of motivation, indecisiveness, dysfunctional beliefs, lack of information, and inconsistent information as the five first-order factors of indecision. The structural validity of this model has been initially supported in subsequent research (Xu \& Tracey, 2015a). However, the data-driven revision is only suggestive of the theory-driven CDDQ model, and a better theoretical articulation is needed for the CDDQ model to solve the theory-data discrepancy. We suspected that lack of motivation, indecisiveness, and dysfunctional beliefs could have different etiologies, and therefore, individuals do not always encounter them simultaneously. For example, indecisiveness could represent a chronic issue related to negative personality traits, while lack of motivation and dysfunctional beliefs could represent developmental issues that can be solved with psychoeducation/counseling.

Structural validity of the CDDQ. Structural validity of the CDDQ concerns whether its theoretically proposed structure could be empirically demonstrated in its administration and has received wide empirical attention. The three-factor structure of the CDDQ in general holds crossculturally, although the lack-of-readiness factor appears less stable than the other two factors (Gati, Osipow, Krausz, \& Saka, 2000; Gati, Saka, \& Mayer, 2000; Mau, 2001; Osipow \& Gati, 1998; Tien, 2005; Xu, et al., 2014).

Criterion validity of the CDDQ. Additionally, there has been a consistent body of research supporting the criterion validity of the CDDQ in the international context (e.g., Creed \& Yin, 2006; Gati \& Saka, 2001a; Lancaster, Rudolph, Perkins, \& Patten, 1999; Xu, et al., 2014). 
For example, Lancaster et al. (1999) revealed a high correlation (.82) between the total CDDQ score with the CDS score, whereas Creed and Yin (2006) found a negative association of the CDDQ scores with career decision-making self-efficacy. Additionally, Gati and Saka (2001a) found that high-school students with a different decision status (undecided vs. decided) showed expected differential scores on the CDDQ. These findings collectively demonstrated the validity of the total CDDQ as a one-dimensional representation of people's career decision-making difficulty. However, since a noticeable advantage of the CDDQ is its potential for a multidimensional diagnosis, research examining the convergent and divergent validity of the CDDQ subscales is potentially more important. As such research is scarce (e.g., Creed \& Yin, 2006; Xu, et al., 2014), the differential functions of the CDDQ subscales remain unclear.

Reliability of the EPCD. Reliability evidence for the EPCD has been documented in the findings of alpha coefficients ranging from .79 to .95 across the three subscales of the EPCD, indicating good internal consistency for each of the three subscales (e.g., Saka \& Gati, 2007; Saka, et al., 2008). Such a pattern has been demonstrated in multiple cultural contexts, such as Israel, the United States, China, Korea, and Turkey (Hou, Li, Liu, \& Gati, 2015; Jin, Nam, Joo, \& Yang, 2015; Oztemel, 2013). Hou et al. (2015) additionally found an adequate test-retest reliability over a two-week interval for the EPCD.

Structural validity of the EPCD. The structural validity of the EPCD has been tested cross-culturally, and there has been convergent evidence supporting the three-factor structure of the EPCD (Hou, et al., 2015; Jin, et al., 2015; Oztemel, 2013; Saka \& Gati, 2007; Saka, et al., 2008). While the research showed that 2 or 3 items loaded on the self-concept and identity domains of the EPCD might not apply to an East-Asian context, the general taxonomy system of the EPCD still holds after deleting those items (Hou, et al., 2015; Jin, et al., 2015). 
Criterion validity of the EPCD. There has been consistent evidence supporting the criterion validity of the EPCD (Hou, et al., 2015; Jin, et al., 2015; Oztemel, 2013; Saka \& Gati, 2007; Saka, et al., 2008). For example, it was found that the EPCD was associated with emotional and personality-related variables, career decision-making self-efficacy, and the CDS (Hou, et al., 2015; Jin, et al., 2015; Saka \& Gati, 2007). It was also found that the EPCD showed differential scores for students with different help-seeking intentions, decidedness, and selfreported difficulties (Gati, Asulin-Peretz, \& Fisher, 2012; Oztemel, 2013; Saka \& Gati, 2007). Longitudinally, the EPCD was found to successfully predict the later decidedness and choice confidence (Gati, et al., 2012; Saka, et al., 2008). However, similar to the validity research of the CDDQ, the divergence of the EPCD factors has been rarely examined in terms of how different factors of the EPCD could differently function in career decision-making and counseling.

Comparison between the CDDQ and the EPCD. Research on the CDDQ and EPCD demonstrated that both measures could reliably and validly assess the theoretically proposed indecision factors, although they have different focal areas of assessment and structural models. Their items exhibit almost complete independence, except one item in lack of readiness of the CDDQ being related to self-concept and identity of the EPCD (i.e., "I am usually afraid of failure”).

\section{Data-Driven Models of Indecision}

The evolution of the data-driven models of indecision has been through roughly two stages, depending on the primary empirical source. The first stage was exemplified by Kelly and Lee’s (2002) innovative study, and the second stage was exemplified by Brown and Rector’s (2008) meta-analysis. 
Factor analysis on indecision measures. Using a factor analysis of the prevailing indecision measures (i.e., CDS, CFI, and CDDQ), Kelly and Lee (2002) explored indecision domains on a college student sample and found six reliable factors: lack of information, need for information, trait indecision, disagreement with others, identity diffusion, and choice anxiety (Kelly \& Lee, 2002). Such a six-factor model largely replicated their initial logical summary of previous factor analytic findings. By analyzing all three generations of indecision measurement (i.e., CDS, CFI, and CDDQ), Kelly and Lee’s (2002) study demonstrated a broader content sampling than previous data-driven research. It should be noted that their study used a sample of college students who had not declared a major. This sample helpfully captured structural information from students experiencing career indecision; however, one could argue that students who have declared a major could also experience career indecision and potentially walk into counseling for assistance. For example, their decidedness of a college major might result from peer/family/societal pressure, rather than a mature decision. Therefore, it is necessary to test the generalizability of Kelly and Lee’s (2002) results in more inclusive samples, especially when the general student population is the target of interventions. Based on this intent, Nauta (2012) showed that only five of the six factors were present in a more diverse student sample. Given the limited content and population sampling in individual studies and the common resultant inconsistency of results, a meta-analysis, which quantitatively extracts factors across multiple samples and measures, appears more powerful. Brown and Rector (2008) described the first meta-analytically derived model of career indecision, which resulted from a factor analytic synthesis of indecision-related variables.

The meta-analytic model of career indecision profile. The meta-analytic model described by Brown and Rector (2008) comprises four factors: neuroticism/negative affectivity 
(NNA), choice/commitment anxiety (CC), lack of readiness (LR), and interpersonal conflicts (IC) (Brown, et al., 2012; Brown \& Rector, 2008). In general, neuroticism/negative affectivity describes a tendency for negative affect, including neuroticism and low self-esteem. Choice/commitment anxiety describes resistance/hesitance to commit to a single choice, including need for information and commitment anxiety. Lack of readiness describes disengagement from the career decision-making process, including low career decision-making self-efficacy and lack of planfulness and goal directedness. Interpersonal conflicts describes disagreement with and discouragement from important people. The four-factor model (Brown, et al., 2012) was later validated in factor analyses of primary data (i.e., an independent sample) and secondary data (i.e., published CDDQ and EPCD correlational matrices). In Brown et al.'s (2012) separate factor analyses on a published CDDQ matrix and a published EPCD matrix, it was found that general anxiety and self-esteem of the EPCD loaded on neuroticism/negative affectivity, lack of information of the CDDQ, uncrystallized identity of the EPCD, and anxiety of the EPCD loaded on choice/commitment anxiety, and inconsistent information of the CDDQ and conflictual attachments of the EPCD loaded on interpersonal conflicts.

Based on the four-factor model, the Career Indecision Profile (CIP) was developed in two forms: a long 167-item version (i.e., CIP-167; Brown, et al., 2012) and an abbreviated 65-item version (i.e., CIP-65; Hacker, et al., 2013). It has been demonstrated that the CIP-65 generally showed good internal consistency, with alpha coefficients ranging from .88 to .97 in a U.S. sample (Hacker, et al., 2013), .72 to .94 in a French-speaking sample (Carr et al., 2014), and .74 to .94 in an Italian sample (Carr, et al., 2014). Hacker et al. (2013) additionally found initial support for the construct validity of the CIP-65 in the findings of the CIP-65 scores being associated with enrollment in career-planning courses and self-reported decidedness levels. 
When examining the cross-cultural validity of the CIP-65, it was found that the general four-factor model held in Western cultures (e.g., Icelandic, Italian, French, and American), although items and factor loadings might not be exactly equivalent (Abrams et al., 2013; Carr, et al., 2014). However, it was repeatedly found that the four-factor structure did not hold in Eastern cultures (e.g., Chinese and Korean) and a separation of choice/commitment anxiety and need for information was consistently revealed (Abrams, Lee, Brown, \& Carr, 2014; Roche, Carr, Lee, Wen, \& Brown, 2017). Roche et al. (2017) proposed two potential reasons: (1) as independence in career decision-making becomes an increasingly salient issue in Chinese and Korean work and cultural contexts, individuals in these two contexts might find information needs particularly salient; and (2) the high levels of future orientation and performance attainment endorsed in both South Korean and Chinese cultures could motivate people to view information collecting as an integral part of the career decision-making process rather than something to worry only when they become anxious and have trouble committing to a career choice. It also appears plausible that individuals from Eastern cultures could perceive choice anxiety and information deficit as two separate difficulties, while individuals from Western cultures could perceive information deficit as the direct cause of choice anxiety and thus perceive them as closely related.

It should be noted that research on the CIP model does not explicitly include identity diffusion as a stand-alone factor of career indecision. However, Brown et al. (2012)’s factor analysis of the CDDQ and EPCD correlational matrices revealed that identity diffusion loaded on the factor of choice/commitment anxiety. As identity diffusion results from a lack of integrated self-knowledge and commitment according to Marcia’s (1966) two-dimensional model of identity status, it is plausible to argue that choice/commitment anxiety and need for information could collectively capture the essence of identity diffusion, although it might be still 
worth examining the relation between identity diffusion and existing factors of the CIP-65 in future research. In fact, Brown et al. (2012) found that similar to identity diffusion, chronic indecisiveness is not a unidimensional construct but rather may have two underlying causes: neuroticism/negative affectivity and choice/commitment anxiety.

In general, while the CIP-65 has demonstrated promising reliability and validity, its length appears inconveniently long for applications in applied and research settings. Therefore, the CIP-Short was developed to increase the efficiency in measuring the four domains of indecision (Xu \& Tracey, 2017b). Using item response theory (IRT), the CIP-Short successfully achieved two major goals: (1) exclude items with confounding information by retaining items only showing a desired monotonic relation of the indecision level with response occurrence, and (2) minimize differential item functioning across gender to enable cross-gender comparisons. Additionally, the CIP-Short showed good internal-consistency reliability, structural validity, convergent/divergent validity, and an excellent ability to capture information obtained in the original CIP-65 (Xu \& Tracey, 2017b). Thus, the CIP-Short currently represents the latest evolvement of indecision measurement, particularly from a data-driven perspective.

\section{Discussion}

As career indecision remains a central topic for career counseling and research, new research (e.g. Brown, et al., 2012; Saka, et al., 2008; Xu \& Tracey, 2017b) has emerged to address its structure and measurement. To assist counselors and researchers in obtaining an updated understanding of indecision structure and measurement, we reviewed the important progress in these areas from 2000 to 2017. Based on our review of theory- and data-driven models of career indecision, we found that a five-factor model could summarize the structural information of career indecision. In addition, we found meaningful cultural variation in 
indecision measurement, which has important implications for multicultural practice of career counseling.

\section{Convergence of Theory- and Data-Driven Models: The Integrative Five-Factor Model}

Although the theory-driven (e.g., the CDDQ and EPCD) and data-driven (e.g., the CIP) models have different developmental paths, research has indicated promising convergence of the two approaches. Based on a logical comparison of the CDDQ, EPCD, and CIP factors, it appeared that five broad and distinct domains of career indecision could be derived to summarize both theory- and data-driven models (see Table 1). The first domain of this five-factor model contains general factors, including neuroticism/negative affectivity of the CIP and general anxiety and self-esteem of the EPCD. This domain describes the tendency to have a pervasive pattern of negative emotional experience. The second through the fifth domains contain career decision-making specific factors. Among them, the second domain contains choice/commitment anxiety of the CIP and anxiety of the EPCD. This domain describes the anxiety arising in the process of making the final choice. The third domain contains lack of information of the CDDQ. This domain describes the difficulty in collecting and processing self- and career-related information. The fourth domain contains lack of readiness of the CIP and lack of readiness of the CDDQ. This domain describes difficulty in initiating career decision-making and a tendency to disengage from the career decision-making process. The fifth domain contains interpersonal conflicts of the CIP and inconsistent information of the CDDQ. This domain describes the inhibitive interpersonal dynamic for career decision-making. We named the five factors after the CIP factors to avoid unnecessary variable proliferation. Interestingly, such a five-factor model has been indicated by the convergent findings of Kelly and Lee’s (2002) and Nauta’s (2012) studies. Moreover, we conducted a factor analysis on Xu and Tracey’s (2017b) published 
correlational matrix, which includes the CDDQ, EPCD, CIP-Short, and Career Decision SelfEfficacy (CDSE; Betz, Klein, \& Taylor, 1996), and found evidence supporting the integrative five-factor model.

\section{The Integrative Five-Factor Model and the CIP}

Given its conceptual and empirical foundations, the new integrative five-factor structure of career indecision shows the potential to achieve a better balance among coverage breadth, model parsimony, clinical meaningfulness, theoretical soundness, and empirical robustness than its parent models. The only difference in this model from the CIP can be seen in choice/commitment anxiety and need for information appearing empirically unified in the CIP model (2012), indicating that these two often occur simultaneously, particularly in Western populations. However, it is plausible to argue that choice/commitment anxiety and need for information have differential causes and require differential clinical interventions, and thus represent two conceptually distinct factors. For example, it is anticipated that need for information could be reduced by a broader and deeper career exploration, but choice/commitment anxiety cannot be alleviated simply by collecting more information, and instead ambiguity tolerance could be more important for it (Xu, et al., 2014; Xu \& Tracey, 2014). Therefore, while it is empirically parsimonious to measure choice/commitment anxiety and need for information together, particularly for Western populations, it is conceptually and clinically important to keep in mind the separation of choice/commitment anxiety and need for information. In this sense, the integrative five-factor model is better than the CIP model in serving the field as the prototype model and conceptual framework of career indecision.

Furthermore, while there has been a long-term effort in the field to seek the single best model of career indecision (Kelly \& Lee, 2002; Osipow, 1999), such a positivism-universalism 
perspective might not serve vocational psychology and career counseling well. One could argue that essentially there might be no single indecision model consistently present across populations, whereas an obsessive search for the "right” model could lead to model proliferation, potentially preventing knowledge accumulation. Therefore, establishing a normative model and several context-specific idiothetic models is recommended for future measurement development of career indecision. Given the current results, the integrative five-factor model has the potential to serve the field as the normative model, while the four-factor model best measured by the CIPShort (Xu \& Tracey, 2017b) could be considered as a cultural variant to the normative model (i.e., an idiothetic model appropriate in Western cultures).

It is worth mentioning that although people in Western cultures collectively perceive choice/commitment anxiety and need for information as two highly related constructs, their individual perception of the two factors might not always adhere to the four-factor model. The potential inconsistency between collective and individual models of career indecision resonates with a similar issue in the assessment of interest. It has been found that although collectively Holland's (1997) model is a good structural representation of interest, individually people could perceive interest types in idiographic ways and such individual interest structures influence career exploration and decidedness (Tracey \& Darcy, 2002; Tracey, Lent, Brown, Soresi, \& Nota, 2006). Therefore, the integrative five-factor model could provide a better assessment framework than the four-factor model of the CIP-Short does, when the focus is on client's individual perception of career indecision. We recommend developing a new CIP scale based on the integrative five-factor model for clinical interventions.

\section{The Integrative Five-Factor Model and the CDDQ}


Using the integrative five-factor model as the guiding framework, the CDDQ mainly contributes to the assessment of two factors: need for information and interpersonal conflicts. The lack of readiness subscale of the CDDQ conceptually fits the five-factor model, but its reliability is weaker than that of the other two subscales. While the five-factor model focuses on broad domains of career indecision, the CDDQ could provide more details regarding different facets within each broad domain (as it has ten subdomains under the three overarching factors). For example, people might exhibit a high general level of need for information, but their needs for different categories of information could vary. Therefore, the CDDQ could be particularly useful if career counselors hope to understand the nuanced profile of need for information and interpersonal conflicts.

\section{The Integrative Five-Factor Model and the EPCD}

Using the integrative five-factor model as the guiding framework, the EPCD mainly contributes to the assessment of two factors: neuroticism/negative affectivity and choice/commitment anxiety. Similar to the CDDQ, the EPCD could provide more details about different faces within each indecision domain than the five-factor model does. Therefore, it is particularly useful when the assessment focus is on various facets of neuroticism/negative affectivity and choice/commitment anxiety.

\section{The Integrative Five-Factor Model and Other Measures of Career Indecision}

To further examine the comprehensiveness of the integrative five-factor model, we compared the five factors with other measures of career indecision, including the Career Decision Scale (CDS; Osipow, et al., 1976), the Career Factors Inventory (CFI; Chartrand, et al., 1990), and the Career Decision Profile (CDP; Jones, 1989). Although there has been some controversy regarding the structure of the CDS, generally research found 
four factors underlying the CDS: diffusion, support, approach-approach, and external barriers (Schulenberg, Shimizu, Vondracek, \& Hostetler, 1988; Shimizu, Vondracek, \& Schulenberg, 1994; Shimizu, Vondracek, Schulenberg, \& Hostetler, 1988). Among the four factors, diffusion reflects a sense of indecision due to various reasons; support addresses career certainty, approach-approach resonates with choice/commitment anxiety of the five-factor model; and external barriers resonate with interpersonal conflicts of the five-factor model. Therefore, it appears that the five-factor model has incorporated the two CDS factors that have direct relevance to antecedents of career decidedness (i.e., approach-approach and external barriers).

We found a similar case when comparing the five-factor model with the CFI and the CDP. There are four factors underlying the CFI: need for career information, need for self-knowledge, career choice anxiety, and generalized indecisiveness (Chartrand, et al., 1990). Notably, the two informational factors resonate with need for information of the five-factor model; career choice anxiety resonates with choice/commitment anxiety of the five-factor model; and generalized indecisiveness resonates with both neuroticism/negative affectivity and choice/commitment anxiety of the five-factor model. Regarding the CDP, there are four underlying factors: self-clarity, knowledge about occupations and training, decisiveness, and career choice importance (Jones, 1989). Among them, self-clarity and knowledge about occupations and training resonate with need for information of the five-factor model; decisiveness resonates with both neuroticism/negative affectivity and choice/commitment anxiety of the five-factor model; and career choice importance resonates with lack of readiness of the five-factor model. Therefore, it appears reasonable to conclude that the five-factor model has incorporated all the factors of the CFI and the CDP. In a summary, the comparative analysis of the integrative five-factor model and all 
major measures of career indecision demonstrated the comprehensiveness of the five-factor model in measuring factors of career indecision.

\section{Cross-Cultural Variance of Career Indecision}

The reviewed research on the cross-cultural variation of career indecision has generally found that the CDDQ, EPCD, and CIP-65 all have sound psychometric performance in terms of reliability and validity across Western and Eastern cultural contexts. While there is structural consistency of the CDDQ (Gati, Osipow, et al., 2000; Gati, Saka, et al., 2000; Mau, 2001; Osipow \& Gati, 1998; Tien, 2005; Xu, et al., 2014) and EPCD (Hou, et al., 2015; Jin, et al., 2015; Oztemel, 2013; Saka \& Gati, 2007; Saka, et al., 2008) in the international context, there is notable structural variance of the CIP between Western and Eastern cultural contexts (Abrams, et al., 2014; Roche, et al., 2017). The divergent findings might result from the fact the CDDQ and EPCD were developed based on universal decision theories, while the CIP was developed based on context-specific data. Although different cultural and work contexts could lead to different relations of indecision factors (see the discussion on the separation of choice/commitment anxiety and need for information), due to its comprehensive coverage, the integrative five-factor model has the potential to serve the field as a guiding framework when comparing career indecision cross-culturally.

\section{Recommendations for Future Research}

Given the current theoretical and empirical progress of indecision measurement, we offer three recommendations for future research. The first recommendation focuses on the divergent nature of the indecision factors. Regardless of the indecision models used, there has been little research exploring how different indecision factors function differently but synthetically in the processes of career decision-making and career counseling (Nauta, 2012). More knowledge of 
the divergent functions of various indecision factors is important and needed to enable a valid and meaningful differential diagnosis in career counseling.

Our second recommendation focuses on the expansion of target populations across the life-span, as the current indecision measurements were primarily developed and administered on high school/college students and young adults. Taking Super’s (1990) life-span and life-space perspective as a guide, it is possible that individuals at different developmental stages could exhibit structural or mean-level differences of career indecision (Vandenberg \& Lance, 2000). Therefore, more information regarding the structural and the mean-level changes of career indecision over the whole life-span is needed.

Our third recommendation focuses on the adoption of an emic approach in examining the cultural variance of indecision (Harris, 1976). As seen in the research of the CIP-65 (Abrams, et al., 2014; Abrams, et al., 2013; Carr, et al., 2014; Hacker, et al., 2013; Roche, et al., 2017), culture plays a significant role in how indecision factors are structured. However, such research still used the U.S.-derived CIP model as the reference without extracting factors broadly in the culture-specific literature. It is thus argued that this etic approach could limit deeper investigation into how indecision factors are structurally related in cross-cultural settings.

\section{Recommendations for Career Counseling}

Our critical review of different career indecision models and measures has revealed various options for exploring career decision-making difficulties from which career counselors can choose. In general, we found that while the CDDQ and the EPCD could assess cognitive, emotional, and personality-related career indecision in detail, the CIP-Short could comprehensively assess broad domains of career indecision. Based on the integrative five-factor 
model of career indecision, we provide several recommendations for career counseling with regard to differential strategies, systematic assessment, and cultural considerations.

Differential strategies. Assessing career decision-making difficulties is crucial for career counseling, as different difficulties often require different intervention strategies. When a client scores high on neuroticism/negative affectivity, it is likely that general anxiety and low selfesteem would be salient issues for counseling. In this case, we recommend that counselors pay close attention to a client's pervasive and persistent patterns of emotion and self-concept and do not focus only on career decision-specific issues (Watson \& Pennebaker, 1989). Interventions designed to improve self-esteem and anxiety management would be particularly important for clients with pervasive self-esteem or anxiety issues, as they help establish a better psychological foundation for career decision-making. Additionally, Brown et al. (2012) suggested that neuroticism/negative affectivity could signal identity foreclosure. Therefore, once career counselors detect an elevation on this dimension, they could explore prematurely foreclosed options and discuss the possibility of reconsidering these options with clients, as clients may have focused on the negative aspects of different options and avoided making decision.

For individuals who experience choice/commitment anxiety, they might have different psychological mechanisms for their commitment anxiety and thus require tailored interventions. For example, choice/commitment anxiety could result from a maximizing decision strategy, as Schwartz et al. (2002) suggested that people using a maximizing strategy tend to seek best career options and experience more decision difficulty and regret. In this case, encouraging clients to adopt a satisficing strategy and seek good enough options would be helpful. Choice/commitment anxiety could also result from dysfunction reactions to decision ambiguity. $\mathrm{Xu}$ and Tracey have found that career decision ambiguity tolerance predicts career decision-making self-efficacy and 
career indecision (Xu \& Tracey, 2014, 2015a, 2015b). To alleviate client’s ambiguity

intolerance, it could be helpful for clients to develop career calling or an organizing structure of interest types and activities adherent to Holland’s model (Xu \& Tracey, 2017a).

For individuals experiencing need for information, counselors could help them collect more information about the self, the vocational word, and the decision-making process. For example, Essig and Kelly (2013) found that information giving was effective in reducing anxiety. There are several excellent informational resources available to the public, such as O*NET Online, that can be a good start for information gathering. If counselors find that clients need comparative information regarding their interest, the Strong Interest Inventory (Donnay, 2005) could be a good tool (Chartrand, Borgen, Betz, \& Donnay, 2002). Notably, need for information and choice/commitment anxiety are often related (as shown by the structural finding in Western cultural contexts), and people could mistake choice/commitment anxiety for need for information. For example, Larson (1988) found that some individuals still engaged in information collecting, although they had already obtained adequate information for career decision-making. Therefore, a deep inquiry of client's psychological mechanism of need for information is important.

For individuals scoring high on lack of readiness, counselors would need to focus on helping them develop self-efficacy beliefs, acquire more rationally focused decision-making skills, and increase goal-directedness and planfulness. Research has found that career decisionmaking self-efficacy is the strongest predictor of changes in decision status overtime (Brown et al, 2012). Social cognitive career theory has suggested that people develop their self-efficacy beliefs through learning experience (Lent, Brown, \& Hackett, 1994). We thus recommend that counselors help clients deliberately learn from their positive experience to enhance decision- 
making self-efficacy. It might be particularly helpful for clients to realize that their counseling experience is also part of their learning experience, in which learning to make a career decision is more important than decidedness itself. In addition to low decision-making self-efficacy, maladaptive perfectionism and avoidance of personal responsibility could also result in disengagement from career decision-making and thus merit clinical attention.

Last, for individuals with interpersonal conflicts, counselors could explore the cultural, family, and relational background of individuals to help them navigate interpersonal disagreement better. It would be important to consider differential cultural orientations (e.g., collectivistic versus individuals) as well as the level of acculturation and enculturation to deepen the case conceptualization of clients’ interpersonal conflicts (Brown et al, 2012). For example, clients from collectivistic cultural contexts often view career decision-making as a collective process and experience a sense of obligation to honor parental expectations. To mitigate client's interpersonal struggle in career decision-making, counselors could use their therapeutic relationship to support clients. Counselors could also teach communication skills to facilitate client's communication/negotiation with parents. Occasionally, client's interpersonal conflicts in career decision-making might reflect a general pattern of interpersonal struggle. If so, it would be beneficial for counselors to help clients change their relational pattern.

Systematic assessment. Counselors could use the CIP-Short in not only an intrapersonal fashion but also an interpersonal manner. The standardized assessment of career indecision using the distributional information of the CIP-Short or the CIP-65 could be particularly useful for normalizing clients’ indecision experience and detecting early symptoms for timely preventions/interventions. In addition, counselors could use the CIP-Short to systematically track the progress of interventions. Given the high efficiency of the CIP-Short, it is possible for 
counselors to assess career indecision in every session over the entire treatment course. By using this feedback-oriented modality, counselors could develop a better sense of the treatment progress and potentially discuss the treatment direction (e.g., termination) when necessary.

Cultural considerations. Our review indicated that individuals in Eastern and Western cultures experience career indecision differently (e.g., Abrams, et al., 2014; Roche, et al., 2017). This has important implications for career counseling, as it shows how culture plays a significant role in career decision-making process. To provide culturally competent career counseling, we recommend that counselors consider individuals' cultural backgrounds in both conceptualizing career decision-making difficulties and using appropriate and effective career counseling approaches. More specifically, because individuals from Eastern cultures have a salient concern regarding need for information from the beginning of their career exploration process (Abrams, et al., 2014; Roche, et al., 2017), it makes sense for counselors to provide interventions designed to increase access to information (Lucas, 1997) from the very beginning. This could include developing and fostering abilities related to self-awareness building as well as understanding of the world of work (Gati \& Saka, 2001a; Wanberg \& Muchinsky, 1992). It could be also important for counselors during treatment planning to be mindful that for individuals from Eastern cultures collecting information cannot completely alleviate choice/commitment anxiety, and other factors, such as ambiguity tolerance (Xu, Hou, Tracey, \& Zhang, 2016; Xu \& Tracey, 2014, 2015b, 2017c), should be also considered.

\section{Conclusion}

Our review indicates that there has been significant progress in the structural models and measurement of career indecision since Osipow (1999) published his seminal article on indecision measurement. We found that the CDDQ (Gati, et al., 1996; Gati, Osipow, et al., 
2000), the EPCD (Saka, et al., 2008), and the CIP-Short (Xu \& Tracey, 2017b) could reliably and validly measure career indecision with different focal areas. We thus recommend the CDDQ and the EPCD as in-depth measures of cognitive and emotional and personality-related indecision, respectively, and the CIP-Short as a comprehensive measure of broad domains of career indecision (particularly in Western cultures). Moreover, an integrative five-factor model shows the potential to comprehensively depict the factor structure of career indecision, consisting of neuroticism/negative affectivity, need for information, choice/commitment anxiety, lack of readiness, and interpersonal conflicts. Based on the five-factor model, we found a meaningful cultural variation of career indecision that compared to individuals in Western cultures, people in Eastern cultures are more likely to perceive need for information as an independent and salient indecision factor (Abrams, et al., 2014; Roche, et al., 2017).

Based on these findings, we recommend several directions for future research and practice. First, it is important to continue exploring the divergent nature of career indecision factors, including their differential etiologies and counseling strategies. Second, the filed needs more research on cultural variations of career indecision, including cross-cultural differences in mean-levels and antecedents of indecision. Last, it would be interesting to explore how to help clients tolerate career indecision. Contemporary perspectives on indecision has emphasized that obsession with decidedness, rather than indecision per se, could be a problem (Krumboltz, 2009; Savickas, 2011). However, research has predominantly focused on indecision reduction, and little is known about how to facilitate a positive relationship between decision-makers and indecision. Career decision ambiguity tolerance could be a viable factor in this direction (Xu \& Tracey, 2014, 2015b). 


\section{References}

Abrams, M. D., Lee, I. H., Brown, S. D., \& Carr, A. (2014). The Career Indecision Profile Measurement Equivalence in the United States and South Korea. Journal of Career Assessment, 1-11. doi: 10.1177/1069072714535028

Abrams, M. D., Omarsdottir, A. O., Bjornsdottir, M. D., Einarsdottir, S., Martin, C., Carr, A., ... Rector, C. (2013). Measurement Invariance of the Career Indecision Profile: United States and Iceland. Journal of Career Assessment, 21(3), 469-482. doi: $10.1177 / 1069072712475181$

Betz, N. E., Klein, K. L., \& Taylor, K. M. (1996). Evaluation of a short form of the career decision-making self-efficacy scale. Journal of Career Assessment, 4(1), 47-57. doi: $10.1177 / 106907279600400103$

Blustein, D. L. (1989). The Development and Validation of a Two-Dimensional Model of the Commitment to Career Choices Process. Journal of Vocational Behavior, 35(3), 342-378.

Brown, S. D., Hacker, J., Abrams, M., Carr, A., Rector, C., Lamp, K., . . Siena, A. (2012). Validation of a Four-Factor Model of Career Indecision. Journal of Career Assessment, 20(1), 3-21. doi: 10.1177/1069072711417154.

Brown, S. D., \& Rector, C. C. (2008). Conceptualizing and diagnosing problems in vocational decision making. In S. D. Brown \& R. W. Lent (Eds.), Handbook of counseling psychology (pp. 392-407). New York, NY: Wiley.

Carr, A., Rossier, J., Rosselet, J. G., Massoudi, K., Bernaud, J.-L., Ferrari, L., . . Brown, S. D. (2014). The Career Indecision Profile Measurement Equivalence in Two International Samples. Journal of Career Assessment, 22(1), 123-137. 
Chartrand, J. M., Borgen, F. H., Betz, N. E., \& Donnay, D. (2002). Using the Strong Interest Inventory ${ }^{\circledR}$ and the Skills Confidence Inventory to Explain Career Goals. Journal of Career Assessment, 10(2), 169-189.

Chartrand, J. M., Robbins, S. B., Morrill, W. H., \& Boggs, K. (1990). Development and validation of the Career Factors Inventory. Journal of Counseling Psychology, 37(4), 491-501.

Constantine, M. G., \& Flores, L. Y. (2006). Psychological Distress, Perceived Family Conflict, and Career Development Issues in College Students of Color. Journal of Career Assessment, 14, 354-369. doi: 10.1177/1069072706286491

Creed, P. A., \& Yin, W. O. (2006). Reliability and validity of a Chinese version of the Career Decision-Making Difficulties Questionnaire. International Journal for Educational and Vocational Guidance, 6(1), 47-63.

Donnay, D. A. (2005). Strong Interest Inventory manual: Research, development, and strategies for interpretation: CPP.

Downing, H. M., \& Nauta, M. M. (2010). Separation-Individuation, Exploration, and Identity Diffusion as Mediators of the Relationship Between Attachment and Career Indecision. Journal of Career Development, 36, 207-227. doi: 10.1177/0894845309345848

Essig, G. N., \& Kelly, K. R. (2013). Comparison of the effectiveness of two assessment feedback models in reducing career indecision. Journal of Career Assessment, 21(4), 519-536.

Gati, I., Asulin-Peretz, L., \& Fisher, A. (2012). Emotional and personality-related career decision-making difficulties: A 3-year follow-up. The Counseling Psychologist, 40(1), 627. 
Gati, I., Krausz, M., \& Osipow, S. H. (1996). A taxonomy of difficulties in career decision making. Journal of Counseling Psychology, 43(4), 510-526. doi: 10.1037/00220167.43.4.510

Gati, I., Osipow, S. H., Krausz, M., \& Saka, N. (2000). Validity of the career decision-making difficulties questionnaire: Counselee versus career counselor perceptions. Journal of Vocational Behavior, 56(1), 99-113.

Gati, I., \& Saka, N. (2001a). High School Students' Career-Related Decision-Making Difficulties. Journal of Counseling \& Development, 79(3), 331-340.

Gati, I., \& Saka, N. (2001b). Internet-Based Versus Paper-and-Pencil Assessment: Measuring Career Decision-Making Difficulties. Journal of Career Assessment, 9(4), 397-416. doi: $10.1177 / 106907270100900406$

Gati, I., Saka, N., \& Mayer, Y. (2000). Internet-based career counseling: Future Directions. The Educational Counselor, 9, 88-110.

Germeijs, V., \& De Boeck, P. (2003). Career indecision: Three factors from decision theory. Journal of Vocational Behavior, 62(1), 11-25.

Germeijs, V., Verschueren, K., \& Soenens, B. (2006). Indecisiveness and high school students' career decision-making process: Longitudinal associations and the mediational role of anxiety. Journal of Counseling Psychology, 53, 397-410. doi: 10.1037/00220167.53.4.397

Hacker, J., Carr, A., Abrams, M., \& Brown, S. D. (2013). Development of the Career Indecision Profile Factor Structure, Reliability, and Validity. Journal of Career Assessment, 21(1), $32-41$ 
Harris, M. (1976). History and significance of the emic/etic distinction. Annual review of anthropology, 5(1), 329-350.

Holland, J. L. (1997). Making vocational choices: A theory of vocational personalities and work environments (3rd ed.). Odessa, FL: Psychological Assessment Resources.

Hou, Z.-J., Li, X., Liu, Y.-L., \& Gati, I. (2015). The Emotional and Personality-Related Career Decision-Making Difficulties Questionnaire_-Validation of the Chinese Version. Journal of Career Assessment. doi: 10.1177/1069072715580565

Jin, L., Nam, S. K., Joo, G., \& Yang, E. (2015). Validation of a Korean Translation of the Emotional and Personality-Related Career Decision-Making Difficulties Scale-Short Form (EPCD-SF). Journal of Career Assessment, 23(2), 294-307.

Jones, L. K. (1989). Measuring a three-dimensional construct of career indecision among college students: A revision of the Vocational Decision Scale: The Career Decision Profile. Journal of counseling Psychology, 36(4), 477-486.

Kelly, K. R., \& Lee, W. C. (2002). Mapping the Domain of Career Decision Problems. Journal of Vocational Behavior, 61(2), 302-326

Krieshok, T. S., Black, M. D., \& McKay, R. A. (2009). Career decision making: The limits of rationality and the abundance of non-conscious processes. Journal of Vocational Behavior, 75(3), 275-290.

Krumboltz, J. D. (2009). The happenstance learning theory. Journal of Career Assessment, 17(2), 135-154. doi: 10.1177/1069072708328861

Lancaster, B. P., Rudolph, C. E., Perkins, T. S., \& Patten, T. G. (1999). CDDQ 效力 The Reliability and Validity of the Career Decision Difficulties Questionnaire. Journal of Career Assessment, 7(4), 393-413. 
Larson, L. M., Heppner, P. P., Ham, T., \& Dugan, K. (1988). Investigating multiple subtypes of career indecision through cluster analysis. Journal of Counseling Psychology, 35(4), 439446.

Lent, R. W., Brown, S. D., \& Hackett, G. (1994). Toward a unifying social cognitive theory of career and academic interest, choice, and performance. Journal of Vocational Behavior, 45(1), 79-122. doi: 10.1006/jvbe.1994.1027

Leung, S., Hou, Z., Gati, I., \& Li, X. (2011). Effects of parental expectations and cultural-values orientation on career decision-making difficulties of Chinese University students. Journal of Vocational Behavior, 78(1), 11-20.

Lipshits-Braziler, Y., Gati, I., \& Tatar, M. (2016). Strategies for coping with career indecision. Journal of Career Assessment, 24(1), 42-66.

Lucas, M. (1997). Identity development, career development, and psychological separation from parents: Similarities and differences between men and women. Journal of Counseling Psychology, 44(2), 123-132.

Marcia, J. (1966). Development and validation of ego-identity status. Journal of Personality and Social Psychology, 3(5), 551-558.

Mau, W. (2001). Assessing career decision-making difficulties: A cross-cultural study. Journal of Career Assessment, 9(4), 353-364.

Nauta, M. M. (2012). Temporal stability, correlates, and longitudinal outcomes of career indecision factors. Journal of Career Development, 39(6), 540-558.

Osipow, S. (1999). Assessing Career Indecision. Journal of Vocational Behavior, 55(1), 147154. 
Osipow, S., \& Gati, I. (1998). Construct and concurrent validity of the career decision-making difficulties questionnaire. Journal of Career Assessment, 6(3), 347-364. doi: $10.1177 / 106907279800600305$

Osipow, S. H. (1994). The Career Decision Scale: How good does it have to be? Journal of Career Assessment, 2(1), 15-18.

Osipow, S. H., Carney, C. G., \& Barak, A. (1976). A scale of educational-vocational undecidedness: A typological approach. Journal of Vocational Behavior, 9(2), 233-243.

Oztemel, K. (2013). Testing the validity of the emotional and personality-related career decisionmaking difficulties questionnaire in Turkish culture. Journal of career development, 40(5), 390-407.

Phillips, S. D. (1997). Toward an expanded definition of adaptive decision making. The Career Development Quarterly, 45(3), 275-287.

Roche, M. K., Carr, A. L., Lee, I. H., Wen, J. H., \& Brown, S. D. (2017). Career Indecision in China: Measurement Equivalence With the United States and South Korea. Journal of Career Assessment, 25(3), 526-536.

Saka, N., \& Gati, I. (2007). Emotional and personality-related aspects of persistent career decision-making difficulties. Journal of Vocational Behavior, 71(3), 340-358.

Saka, N., Gati, I., \& Kelly, K. R. (2008). Emotional and Personality-Related Aspects of CareerDecision-Making Difficulties. Journal of Career Assessment, 16(4), 403-424.

Santos, P. J., \& J., P. (2001). Predictors of Generalized Indecision Among Portuguese Secondary School Students. Journal of Career Assessment, 9, 381-396. doi: $10.1177 / 106907270100900405$ 
Savickas, M. L. (2011). Career counseling. Washington, DC, US: American Psychological Association.

Savickas, M. L. (2015). Career Counseling Paradigms Guiding, Developing and Designing (Vol. 1, pp. 129-143).

Schulenberg, J. E., Shimizu, K., Vondracek, F. W., \& Hostetler, M. (1988). Factorial invariance of career indecision dimensions across junior high and high school males and females. Journal of Vocational Behavior, 33(1), 63-81.

Schwartz, B., Ward, A., Monterosso, J., Lyubomirsky, S., White, K., \& Lehman, D. R. (2002). Maximizing versus satisficing: happiness is a matter of choice. Journal of Personality and Social Psychology, 83(5), 1178.

Shimizu, K., Vondracek, F. W., \& Schulenberg, J. (1994). Unidimensionality versus multidimensionality of the career decision scale: A critique of Martin, Sabourin, Laplante, and Coallier. Journal of Career Assessment, 2(1), 1-14.

Shimizu, K., Vondracek, F. W., Schulenberg, J. E., \& Hostetler, M. (1988). The factor structure of the Career Decision Scale: Similarities across selected studies. Journal of Vocational Behavior, 32(2), 213-225.

Slaney, R. B. (1988). The assessment of career decision making. In W. B. W. S. H. Osipow (Ed.), Contemporary topics in vocational psychology. Career decision making (pp. 3376). Hillsdale, NJ, US: Lawrence Erlbaum Associates, Inc.

Super, D. E. (1990). A life-span, life-space approach to career development. In D. Brown \& L. Brooks (Eds.), Career choice and development: Applying contemporary theories to practice (2nd ed.). (pp. 197-261). San Francisco, CA, US: Jossey-Bass, San Francisco, CA. 
Super, D. E. (1994). A life span, life space perspective on convergence. In M. L. Savickas \& R. W. Lent (Eds.), Convergence in career development theories: Implications for science and practice. (pp. 63-74). Palo Alto, CA, US: CPP Books.

Tien, H. (2005). The Validation of the Career Decision-Making Difficulties Scale in a Chinese Culture. Journal of Career Assessment, 13(1), 114-127.

Tinsley, H. E. (1992). Career decision making and career indecision. Journal of Vocational Behavior, 41(3), 209-211.

Tracey, T. J. (2010). Relation of interest and self-efficacy occupational congruence and career choice certainty. Journal of Vocational Behavior, 76(3), 441-447.

Tracey, T. J., \& Darcy, M. (2002). An idiothetic examination of vocational interests and their relation to career decidedness. Journal of Counseling Psychology, 49(4), 420-427.

Tracey, T. J., Lent, R. W., Brown, S. D., Soresi, S., \& Nota, L. (2006). Adherence to RIASEC structure in relation to career exploration and parenting style: Longitudinal and idiothetic considerations. Journal of Vocational Behavior, 69(2), 248-261.

Vandenberg, R. J., \& Lance, C. E. (2000). A review and synthesis of the measurement invariance literature: Suggestions, practices, and recommendations for organizational research. Organizational research methods, 3(1), 4-70. doi: 10.1177/109442810031002

Vertsberger, D., \& Gati, I. (2016). Career Decision-Making Difficulties and Help-Seeking Among Israeli Young Adults. Journal of Career Development, 43, 145-159. doi: $10.1177 / 0894845315584162$

Wanberg, C. R., \& Muchinsky, P. M. (1992). A typology of career decision status: Validity extension of the vocational decision status model. Journal of Counseling Psychology, 39(1), 71-80. 
Watson, D., \& Pennebaker, J. W. (1989). Health complaints, stress, and distress: exploring the central role of negative affectivity. Psychological review, 96(2), 234-254.

Xu, H., Hou, Z.-J., \& Tracey, T. J. G. (2014). Relation of environmental and self-career exploration with career decision-making difficulties in Chinese students. Journal of Career Assessment, 22, 654-665. doi: 10.1177/1069072713515628

Xu, H., Hou, Z., Tracey, T. J. G., \& Zhang, X. (2016). Variations of career decision ambiguity tolerance between China and the United States and between high school and college. Journal of Vocational Behavior, 93, 120-128. doi: 10.1016/j.jvb.2016.01.007

Xu, H., \& Tracey, T. J. G. (2014). The Role of Ambiguity Tolerance in Career Decision Making. Journal of Vocational Behavior, 85, 18-26. doi: 10.1016/j.jvb.2014.04.001

Xu, H., \& Tracey, T. J. G. (2015a). Ambiguity Tolerance With Career Indecision: An Examination of the Mediation Effect of Career Decision-Making Self-Efficacy. Journal of Career Assessment, 23, 519-532. doi: 10.1177/1069072714553073

Xu, H., \& Tracey, T. J. G. (2015b). Career Decision Ambiguity Tolerance Scale: Construction and initial validations. Journal of Vocational Behavior, 88, 1-9. doi: 10.1016/j.jvb.2015.01.006

Xu, H., \& Tracey, T. J. G. (2017a). Career Decision Ambiguity Tolerance and Its Relations With Adherence to the RIASEC Structure and Calling. Journal of Career Assessment, 25(4), 715-730. doi: 10.1177/1069072716665874

Xu, H., \& Tracey, T. J. G. (2017b). Development of an abbreviated career indecision profile-65 using item response theory: The cip-short. Journal of Counseling Psychology, 64(2), 222232. doi: $10.1037 / \mathrm{cou} 0000182$ 
Xu, H., \& Tracey, T. J. G. (2017c). The Reciprocal Dynamic Model of Career Decision Ambiguity Tolerance With Career Indecision: A Longitudinal Three-Wave Investigation. Journal of Counseling Psychology, 64(5), 538-549. doi: 10.1037/cou0000220 
Table 1. Summary of Indecision Factors across the CIP, the CDDQ, and the EPCD

\begin{tabular}{|c|c|c|c|c|}
\hline \multicolumn{2}{|c|}{ CIP } & \multirow{3}{*}{ CDDQ } & \multirow{3}{*}{ EPCD } & \multirow{3}{*}{ The Integrative Five-Factor Model } \\
\hline CIP in Western & CIP in Eastern & & & \\
\hline cultures & Cultures & & & \\
\hline \multirow[t]{2}{*}{ Neuroticism/Ne } & Neuroticism/Ne & & & \\
\hline & & & General Anxiety and Self & general anxiety, low self-esteem, and pervasive \\
\hline gative & & & $\Gamma$ (tos & . \\
\hline \multirow[t]{3}{*}{ Affectivity } & Affectivity & & & \\
\hline & Choice/Commit & & & \\
\hline & & & Anxiety & difficulty in committing to a single career choice \\
\hline \multirow{4}{*}{$\begin{array}{l}\text { Choice/Commit } \\
\text { ment Anxiety }\end{array}$} & ment Anxiety & & & \\
\hline & Need for & Lack of & & \multirow{3}{*}{ lack of decision-related information } \\
\hline & & & & \\
\hline & Information & Information & & \\
\hline Lack of & Lack of & Lack of & & difficulty in initiating career decision-making, or \\
\hline Readiness & Readiness & Readiness & & tendency to drop out \\
\hline \multirow[t]{2}{*}{ Interpersonal } & Interpersonal & Inconsistent & & \multirow{3}{*}{ disapproval from important people } \\
\hline & & & & \\
\hline Conflicts & Conflicts & Information & & \\
\hline
\end{tabular}

Note. CIP = Career Indecision Profile. CDDQ = Career Decision Difficulties Questionnaire; EPCD = Emotional and Personality

Career Difficulties Scale. 